NASA-TM-111241

Pergamon

Adv. Space Res. Vol. 14, No. 11, pp. (11)357-(11)366, 1994 1994 COSPAR

Printed in Great Britain. $0273-1177 / 94 \$ 7.00+0.00$

\title{
DYNAMICS OF MICROORGANISM POPULATIONS IN RECIRCULATING NUTRIENT SOLUTIONS
}

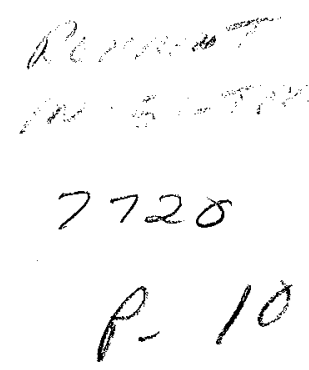

\author{
R. F. Strayer \\ The Bionetics Corporation in support of the NASA Biomedical Operations and \\ Research Office, Kennedy Space Center, FL, U.S.A.
}

\begin{abstract}
This overview covers the basic microbial ecology of recirculating hydroponic solutions. Examples from NASA and Soviet CELSS tests and the commercial hydroponic industry will be used. The sources of microorganisms in nutrient solutions include air, water, seeds, plant containers and plumbing, biological vectors, and personnel. Microbial fates include growth, death, and emigration. Important microbial habitats within nutrient delivery sytstems are root surfaces, hardware surfaces (biofilms), and solution suspension. Numbers of bacteria on root surfaces usually exceed those from the other habitats by several orders of magnitude. Gram negative bacteria dominate the microflora with fungal counts usually much lower. Trends typically show a decrease in counts with increasing time unless stressed plants increase root exudates. Important microbial activities include carbon mineralization and nitrogen transformations. Important detrimental interactions include competition sith plants, and human and plant pathogenesis.
\end{abstract}

\section{INTRODUCTION}

The primary goal of many intensive crop production systems has been to harvest maximal crop yields with minimal costs in time. volume, mass, energy, manpower, and money. Commercial hydroponics ventures and space-related crop production systems-both NASA and former Soviet programs in Controlled Ecological Life Support Systems (CELSS)--accomplish this goal by growing crops in controlled greenhouse or chamber environments to eliminate as many limiting factors as possible. Parameters such as light intensity, light quality, day length, carbon dioxide concentration, temperature, relative humidity, and inorganic nutrient concentrations are set at levels known to provide high crop productivity.

To ensure that inorganic nutrients are provided continually to these rapidly growing crops, recirculating nutrient delivery systems are commonly employed. The solution may flow through various inert, and not so inert, solid media (rock wool, lunar regolith, arcillite, sand, gravel, etc.) or without media in thin nutrient film technique (NFT) or deeper solution culture. As nith nearly all plant production ecosystems, either natural or agricultural, recirculating solution systems are inhabited by a distince, indigenous microflora. As aptly put by Alexander /1/, "the environment selects", and the microflora that are sustained are a result of the unique combination of biotic and abiotic environmental parameters that characterize recirculating crop growth systems.

The environmental parameters in recirculating systems are all set to optimize crop production and minimize stress on the plants /14/. In attempts to keep these parameters within optimal production ranges, tight control measures are often employed to minimize flucuations. The recirculating system microflora are, of course, also exposed to this narrowly defined environment and, "the environment selects" /1/. For much of the recirculating solution ecosystem, the parameter levels set for crop production also support microbial growth and production.

The title of this COSPAR symposium suggests the need to control the microflora that inhabit recirculating systems. Ideally, all crop roots are in immediate contact with the recirculating nutrient solution, but this means that potential problems, including plant root pathogens, will be dispersed rapidly. As an example, in the cultivation of crops in the Biomass Production Chamber (BPC) at the Kennedy Space Center CELSS Breadboard Facility, each $4 \mathrm{~m}^{2}$ of growing area is serviced by $200 \mathrm{~L}$ of nutrient solution at a $16 \mathrm{~L}$ min $^{-1}$ flow rate $/ 2 /$. Upon occurrence, a microbial problem could take about 12.5 minutes to contaminate the entire system, with homogeneous, even dispersal.

However, only a small fraction of the microbial species present in recirculating systems would be able to cause phytopathogenic problems. To control unselectively the non-pathogenic microorganisms along with the plant pathogens would likely cause a con- 
comitant decrease in the role or function of the non-pathogens. The other two invited papers for this symposium focus on the plam pathogens $/ 3 /$ and on the control of microbes $/ 4 /$ in recirculating systerns. This paper will focus on the microbial ecology of the noophytopathogenic microflora. Admittedly, some of these also cause problems (e.g., conversion of nitrogen into forms not utilized by the plants), but most are either beneficial to plants or, at least, do not cause significant reductions in crop yields.

Unfortunately, the microbiological literature on recirculating systems is sparse, with relatively few reports of microbial activity from the commercial hydroponics industry and NASA and former Soviet CELSS. Therefore, the voluminous literature on similar habitats-soil, rhizosphere, and nicrobial biofilms-ivill be used where needed to support principles of microbial ecology that I believe are important in recirculating systems. In addition, research needs for recirculating systems will be identified as the paper progresses.

\section{SOURCES OF MICROBIAL DNOCULA}

A brief presentation of the major inputs of microorganisms to recirculating systems is useful. However, the microbial composition of each source reflects the environmental selective pressures of that source, and does not indicate which microbes will succed in the new environment. Often, little attempt is made to control these microbial sources because of the uncertainty that such measures have any effect on crop yields and because, in large scale production systems, treating each source becomes impractical. Also, at least at Kennedy Space Center, the working pathogen control philosophy is to treat problems as they occur. The reason for this is simple: the range of possible pathogens is large and the need to control microbial sources has not been demonstrated. Some obvious potential plant pathogen sources, such as seed surfaces, were treated initially, but subsequent crop production studies even eliminated this basic measure without any obvious decrease in yields.

\section{Water}

Most CELSS crop producing systems now use de-ionized (DI) water sources but the ultimate CELSS goal is to use recycled (e.g., dehumidifier condensate) water. Most commercial recirculating systems seem to use the least expensive source available, usually; municipal or well water. These sources all contain microorganisms, but concentrations and species composition vary. Nutrient concentrations are very low in all of these water sources and, thus, the dominant microbes are ones that do best under these conditions. Counts of viable bacteria in $\mathrm{DI}$ and condensate water usually range between $10^{4}$ to $10^{6}$ per mL $/ 5 \%$. For municipal water (treated). viable counts are considerably lower due to treatment. Viable bacterial counts for well water are very source dependent, but usually low, with occasional samples above $10^{6}$ per $\mathrm{mL}$.

Bacteria that have been isolated from DI and condensate water and identified include Pseudomonas testosteroni, Ps. pickettii, Ps acidovorans, Ps. mesophilica, Ps. vesicularis, and Ps. paucimobilis with occasional Flavobacterium (Sphingobacterium) and Alcaligenes species $/ 5,61$. Most of these could best be characterized as rather slow growing oligotrophs. Within the water distribution system. these bacteria have probably colonized internal surfaces and grow, albeit slowly, on the low level of organic compounds leaching from various components. Their occurrence suspended in the nater reflects sloughing of biofilm material.

Other potential water sources for CELSS recirculating systems have been a focus of recent NASA research. Scientists at Ames Reserch Center (ARC) have added simulated washwater and showerwater, containing a detergent, to lettuce recirculating solutions 71. At KSC, the resource recovery subsystem has regenerated crop mineral nutrients through the aqueous extraction of inedible crop residues $18-9 \%$. These solutions contain soluble organic compounds in additon to the recycled minerals. In other studies, the KSC scientists have also grown high densities of fish (tilapia) in both wheat and lettuce hydroponic solutions $/ 10 \%$. In all three of these examples, the solutions contained, or will contain, high levels of both microorganisms and easity degraded organic compounds. The crop leachate solution is probably of most concern to plant pathologists because it is derived from plant material and no doubt contains plant-associated microbes. However, this nutrient regeneration route has proven very promising because it easily returns many important elements back to the plants.

Air

Air is a good dispersal agent for microorganisms, but few, if any, actually grow and proliferate there. Morphological survival forms, e.g., fungal and bacterial spores, seem to dominate over vegetative forms, probably because they tolerate desiocation better. To provide a significant microbial inoculum to recirculating nutrient solutions, large volumes of air must contact the solution. Some CELSS crop production systems now use high efficiency particulate air (HEPA) filters to remove airborne contaminants, which reduces the air-solution interface route of entry of microbes into the solution. At the other extreme, massive aeration by sparging large volumes of unfiltered air through solutions would certainly contribute a significant microbial inoculum. For reference, counts of airborne fungi in Florida (Cape Canaveral Air Force Station) range from 100 to 1000 colony forming units (cfu) per cubic meter and bacteria range from 100 to $1000 \mathrm{cfu} \mathrm{m}^{-3}$. Fungal counts are almost always higher than bacterial ones $/ 5 /$, while in the HEPA filtered $\mathrm{BPC}$ they are less than $1 \mathrm{cfu} \mathrm{m}^{-3}$. 


\section{Plant Materials}

The most obvious sources of indigenous plant-associated microorganisms, either pathogenic or not, are plant materials. These materials can be categorized into seeds, living plants, and plant debris.

Plant propagules. Microorganisms can be found on the external surfaces of virtually all (untreated) seeds. Microscopic examination reveals individual cells and small aggregates on smoothet areas of seed coats as well as within grooves and convolutions in the seed coat. Seed coats are often not tightly attached to the seed proper, and microbes can often be found underneath the coat. Incubation of uater-soaked seeds for several days in a moisture chamber results in a virtual explosion of fungal growth and, with time, fungal fruiting structures. Most are "field fungi" such as Aspergillus, Penicillium, Mucor or Rhizopus, and Alternaria /6.11/.

Surface sterilization of seeds is offen used to control this problem, but microorganisms have also been found in the interior of many crop seeds $/ 12 \%$. To eliminate these microbes would require longer sterilization exposure times, higher concentrations or harsher chemicals. Most of these antimicrobial treatments can also kill the seed embryo.

Plants are also propagated by tissue and cell culture techniques. The resulting plantlets are usually sterile and do not contain microbial inocula.

Living plants. Eventually, CELSS will continously produce crops with recirculating solution systems. If all plants share the same solution, without some sort of age compartmentalization, newly germinated seeds or freshly transplanted sterile plantets will be inoculated by contact with solutions used to grow the previous crop of plants. To date, only a few studies have cultured crops continuously over several life cycles on the same solution /13\%. The preponderance of crop recirculation studies have used batch cultivation with all plants germinated, grown to maturity, and harvested at one time.

Plant debris. Plants in any recirculating system should not be intentionally exposed to plant debris. However, leaf litter may not be noticed and enter nutrient solutions, and incomplete cleaning techniques may leave broken root sections in delivery system hardnare. This debris will readily provide a source of plant-associated microorganisms.

\section{Delivery System Harduare}

Newly manufactured delivery system hardware should be almost sterile. But after being used only once to grow crops in a recirculating solution. the wetted surfaces will be heavily colonized by a microbial biofilm. Biofilms are a major microbial habitat in recirculating systems and will be covered in more detail later. Prior to reuse, hardware is usually given a general clearing, often by disinfecting agents such as hypochlorite or acid solutions.

\section{Crew/Personnel}

Crew contact with solutions, plants, equipment, instruments, and delivery systems hardware can contribute microbial inocula. The major concern to plant pathology would be human vectors, especially if they came directly from contaminated plant grouth chambers or greenhouses without disinfection. Clothing, including shoes, can carry plant debris and soil from outside the plant growth area and thus contribute microbial inocula. Preventive measures are sometimes employed and include hypochlorite step baths. and disposable covers over hair, shoes, hands, and clothing. The indigenous human epidermal and mucosal microflora are another inoculum source and are fairly well known, but their impact on the nutrient solution microbial community is not well defined.

\section{MICROBIAL HABITATS}

Three distinct microbiological habitats exist within a recirculating system: the solution, root surfaces, and hardware surfaces. The microflora of the nutrient solution habitat are suspended in water, either as free-living cells or attached to suspended particulates. The root surface (termed rhizoplane) habitat includes attached microorganisms, whether tightly bound, imbedded in mucigel, or easily dislodged. The microbes associated with the hardware surface habitat(s) are attached in biofilms to these wetted, non-living surfaces. Although the nutrient solution is considered a separate habitat, it also acts to transport/disperse organic, inorganic, and microbic constituents to the other two habitats.

\section{Hydroponic Solution}

Habitat description. Solutions are well aerated to support root respiration, so aerobic microorganisms also have enough dissolved oxygen for normal respiratatory functions. Not only is oxygen necessary for root and microbial respiration, but it also totally dominates the redox potential. Root solution temperatures are adequate for mesophilic microorganisms. As with other non-thermoregulated organisms, microbial growth and metabolic rates are faster at higher temperatures within their upper tolerance limit. 
Solution $\mathrm{pH}$ tends to vary with the crop, but for whear. soybeans and potatoes it is commonly kept near 6.0. Bacteria usually grow and metabolize faster at a pH nearer neutrality and fungi usually do better at a lower $\mathrm{pH}$. Nevertheless, a pH of 6 is well within the tolerance range for either group. Related to $\mathrm{pH}$, the solutions are not well buffered and bulk solution $\mathrm{pH}$ is controlled by the addition of acid or base. In the absence of a strong buffer, the $\mathrm{pH}$ at local microhabitats could be considerably different from the bulk $\mathrm{pH}$.

Inorganic nutrients are also optimized for crop production. Nitrogen is usually supplied as nitrates or a combination of nitrates and ammonium. Not surprisingly, microbes can use either $\mathbf{N}$ source. Phosphate, sulfur (as sulfate), calcium, magnesium, and chelated iron are more than adequate for microbial needs. Potassium is in abundant supply and a macronutrient for plants and is essentially a micronutrient for microorganisms. As the trace elemem content is designed for plants, some elements required by some members of the microbial community may be missing and some may be at limiting concentrations.

Along with the other environmental parameters just discussed, crop physiologists attempt to provide sufficient light and carton dioxide supplies also to optimize crop growth. However. these energy and carbon sources are of little direct use to the predominantly heterotrophic microflora that inhabit the recirculating nutrient solution. The paucity of preformed, utilizible organic carbon compounds is the prime factor responsible for limiting mictobial growth and activity. The total organic carbon content of recirculating solutions is typically very low and levels of specific, individual organic compounds are nearly below detection limits. In addition. these compounds are supplied to the solution at very slow rates through rhizodeposition of root exudates, sloughed root cells, and root excretion of mucilage. A much less important source of organic compounds is soluble compounds leached from inert hardware materials such as PVC plastics, glues, paint solvents, and other plastics.

Trends in temporal and spatial abundance and distribution. Conventional microbiological enumeration techniques, including direct and viable counts, have been used to characterize the microbial ecology of recirculating systems $15,15-17 /$. Unfortunately, methodological differences between studies make comparisons of specific results difficult. A few conclusions, however, are evident regardless of the crop species, recirculating system senup, or microbiological techniques and media. (For a review of methods used to estimate microbial biomass, see Atlas $/ 18 /$ )

In batch crop production systems, counts of total bacteria (either direct or viable counts) in the nutrient solution are highest during seed germination and seedling growth $(0-2$ weeks) $/ 5 /$ (Figure 1 ). This probably reflects the bacterial content of the source water and the high rates of seedling root exudation. Other influences on solution microflora at this stage of crop development are, themselves, not yet well developed. Although root exudation is high, seed and seedling root biomass is extremely small relative to later growth stages. Similarly, hardware biofilms are in initial stages of colonization. As the crop matures, progressing from a vegetative growth stage into a reproductive one, the solution bacterial counts steadily decline until, near crop senescence and harvest, numbers have often dropped by more than an order of magnitude lower than seedling stages. Of course, trends counter to this general scenario can be found $/ 16-171$, and fluctuations in the "steady decline" also occur. Bacterial counts have also been obtained for more specific bacterial groups (e.g., actinomycetes $/ 16 /$ or the pseudomonads $15 /$, and non-taxonomic functional groups (e.g., aerobic cellulose degraders, denitrifiers, ammonifiers, etc)/16/. To add to this confusion, some of these enumeration

\section{Bacteria (cfu/mL)}

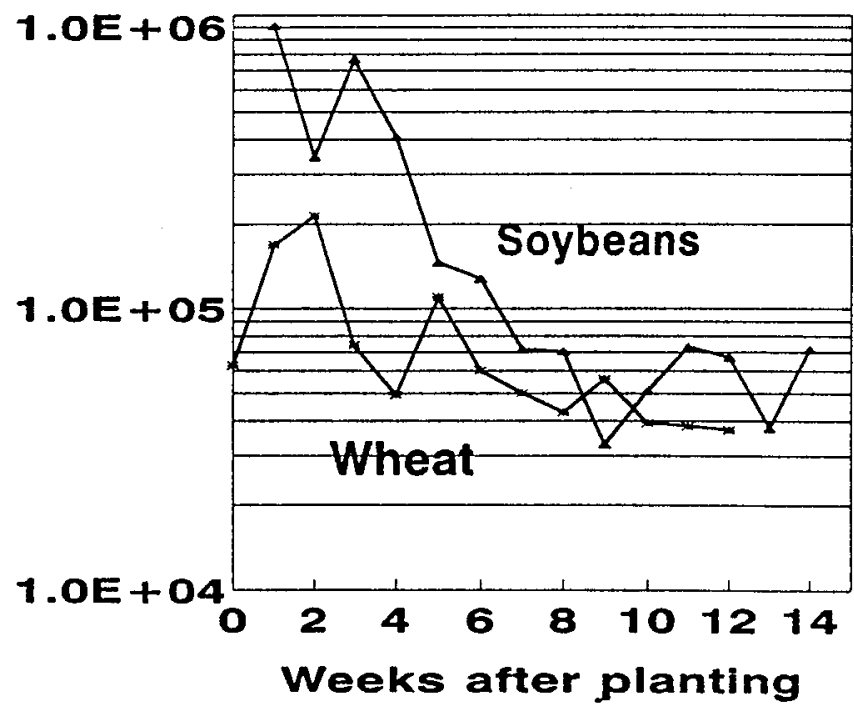

Fig. 1. Concentrations of total viable bacteria suspended in recirculating hydroponic solution during cultivation of wheat (asteriks) and soybeans (closed triangles) in the Biomass Production Chamber (BPC) at the Kennedy Space Center CELSS Breadboard Facility. For wheat each point is the average of 24 samples (2 BPC nuns--from seeding to harvest, 4 nutrient delivery systems, three replicate samples), and for soybean each point is the average of 36 samples $(3 \times 4 \times 3)$ 
results run counter to the total viable numbers, some track them closely, and others appear more or less random $/ 5 /$.

Fungal populations are most often estimated by viable counting lechniques, although microscopic examination of stained preparations is also used. A valid criticism of viable fungal counts is that they are hard to interpret because the developing colonies on the fungal enumeration nedium may have resulted from an inactive spore, an active or inactive vegetative cell or piece of hypha. Furthermore, the hyphae may have been fragmented by dispersive sample preparation techniques, thus artificially increasing the fungal viable counts. Given these caveats, viable fungal counts are usually orders of magnitude lower than bacterial counts $/ 5 /$.

The microorganisms suspended in solution are barely growing $/ 19 /$ with a median biomass turnover rate of 80 days. This is not unexpected as levels of utilizable carton and energy sources (the factors limiting microbial growth in solutions) range between undetectable and very low. With biomass tumover so slow, the gradual decrease in microbial numbers with time probably reflects fates such as predation, differences in emigration/immigration (to/from root surfaces and biofilms) or even removal of suspended particulates (and attached microflora) by fibrous root mats (for wheat and soybeans, the root mat fills the containers by week six).

Microbial community taxonomic composition. The most complete assessments of microbial community composition in recirculating solutions have been from a bacterial taxonomic perspective $15,15-17 \%$. The most frequently encountered bacterial genus has been Pseudomonas, with species names commonly found associated with plants, i.e. Ps. stutzeri, Ps. vesicularis, Ps. paucimobilis, and Ps. fuorescens. Other gram negative genera isolated from solutions have included Flavobacterium (Sphinogobacterium), Enwinia (herbicola), Achromobacter, and Agrobacterium. The most common gram positive genus is Bacillus, but some Staphylococcus and Sireptococcus (not necessarily human pathogenic species), and unindentified gram positive cocci are also found occassionally. Little work seems to bave been done to isolate and identify Actinomycetes in the solution.

\section{Root Surface}

Habitat description. A large volume of literature exists on the rhizosphere, including some excellent reviews /20-21/ and books $/ 22$ 24\%. For soils, the rhizosphere has a practical definition: the root and soil that still clings to it after a gentle shaking. For hydroponic solutions, this definition fails. As scon as the root is taken from the solution, the three dimensional structure collapses as the water drains from the mat. For hydroponic solutions the more restrictive term, rhizoplane, or root surface, is more accurate. A significant difference betwcen crop species exists with regard to root morphology and structure, growth, development, function, and exudation. Thus, one would expect the microflora to be different, too.

Because roots of crops grown in recirculating systems are continually bathed with hydroponic solution, many characteristics of this habitat are similar to those of the solution. However, the root is the primary source of all available carbon and energy entering a recirculating ecosystem. Root exudation rates vary with crop species and age, etc., but a typical range is 20 to $60 \mathrm{mg} \mathrm{g}^{-1}$ root dry weight day ${ }^{-1} / 25 /$. As a result of this exudation, the root surface is densely colonized by microorganisms. Both the root and attached microflora can cause drastic local changes to the solution chemistry of the microhabitat as inorganic nutrients are taken up, as respiration consumes oxygen and produces carton dioxide, and as other metabolic functions alter other chemistries (e.g., $\mathrm{pH}$ changes, redox changes, nitrogen transformations).

Because localized oxygen depletion might occur when microbial and root respiration removes oxygen faster than diffusion can replace it, the possibility exists for anaerobic zones within a root mat. This situation is most likely to occur in stagnant areas where organic compounds fuel rapid respiration, such as in thicker root mat areas or where solutions follow channels through the mat, leaving diffusion to supply oxygen to areas distant from the channel. In oxygen depletion zones some undesirable (for the crop) anaerobic microbial processes are possible, including denitrification, sulfate reduction/hydrogen sulfide production, and organic acid production, etc.

Temporal and spatial abundance and distribution. Microscopic examination of plant roots reveals that bacteria colonize only about 4 to $10 \%$ of the root surface $126 \%$. Most occur at locations where root exudation is active-the growing root tip, imbedded within the mucigel (bacterial and plant exopolysaccharides) and at junctions betreen root surface cells, where leakage of organic compounds occurs $/ 23,25 /$.

Of these microsites, the growing tip is most active and thus, so are the bacteria closest to it. The further attached bacteria are from the tip, the more likely they are to undergo nutrient (carbon) limitation. Most microbiological studies do not examine the root surface at this scale, but, instead, take much larger samples of either the root mat or, even, the whole root, from tip to crown. These samples include attached bacteria from the metabolic range of actively growing (probably a minor component of this sample) to those that are nutrient limited, starved, scenescent, or even moribund.

Figure 2 shows the density of viable bacteria occurring on soybean roots $/ 5 /$ and of total bacteria (microscope counts after acridine orange staining, from Garland/27/) occurring on wheat roots during recirculating nutrient growth. Although, in this example, the 


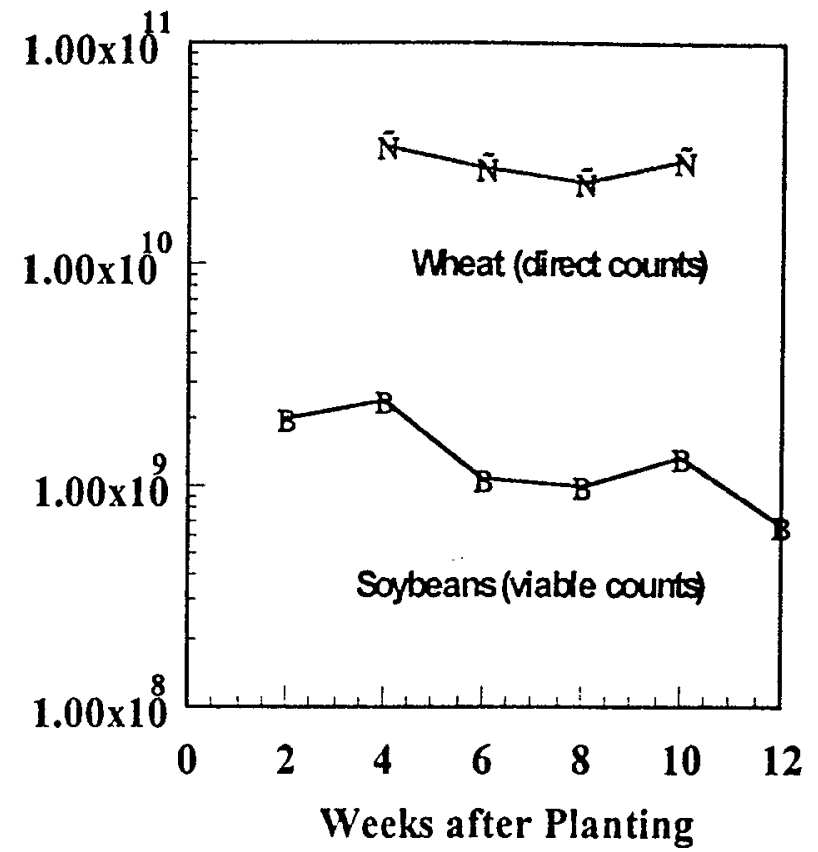

Fig. 2. Density or concentration of bacteria on the surface of wheat (lotal direct counts [acridine orange stain-epifuorescence microscopy] of Garland /27/) and soybeans (total viable counts [spread plate counts on R2A medium] of Strayer /5). temporal trend for viable bacteria is again in decline as for the solution, the rate of change is not as great. For the total counts on wheat. the trend is more stable and shows little decline. These plots of bacterial concentration do not tell the complete story, however. The crop root mass increases from seod germination through closure of the root mat and on into the crop's reproductive growth stage. Eventually, either through spatial limitations or crop maturation, root growth stops. Thus, the absolute numbers of bacteria increase as the root mass increases, even though the density of microbes on the root does not change or declines slightly.

Microbjal community composition(taxonomic). The bacterial taxa identified as present on crop root surfaces are similar to those present in the nutrient solution. However, the proportions are often different. Pseudomonos sometimes dominates, with Achromobacter and Flavobacterium also quite common, Figure 3 /5,15-17/. As expected, differences in community composition can be detected with different crops. However, temporal changes, i.e., succession, do not seem to occur $/ 5 \%$. This finding runs counter to what is expected, and can probably be explained by the fact that the isolates come from bulk root samples, with root tissue and bacteria of many different ages contributing to the community analysis. If examined on a microhabitat scale, the bacterial community would probably be found to change with time.

\section{Hardware Surface}

The most glaring deficiencies in recirculating solution microbial ecology are detailed analyses of hardware suface biofilms. No literature was found for commercial growers or former Soviet CELSS. The NASA CELSS project at KSC has examined hardware surfaces only twice to date: once each for wheat and white potato (a second white potato study is in progress). In CELSS related research, Garland examined recirculating system hardware surfaces during research on wheat culture $/ 27 \%$, and another investigator is currently examining biofilm microbial ecology for NASA.

Habitat description. The literature on microbial biofilms is extensive. The stages of biofilm development on a newly exposed surface (substratum) are well known $/ 28$. The surface is prepared for colonization by adsorption of organics from solution to form a conditioning film. Bacteria in the solution attach (several stages included), grow on absorbed and solution organics, and multiply, eventually forming a noticeable accumulation of microbial cells and exopolymeric material.

The growth of a biofilm is similar to a microbial growth curve with stages of induction, logarithmic accumulation, and a plateau 129\%. The plateau is a dynamic condition with attachment and detachment of cells, entrapment and release of other particulates, and cell growth, death, predation, etc. Any surface in contact with aqueous solutions will eventually form a biofilm. Because the biofilm cells are embedded in an exopolymeric matrix, diffusion limits the transport of nutrients to the cells and metabolic products away from the cells. Thick biofilms can even develop anaerobic zones due to these diffusional linitations and microbial oxygen consumption through respiration.

Temporal and spatial abundance and distribution. The limited data sets available indicate that wetted surfaces are colonized with bacteria, at densities ranging from $10^{4}$ to $10^{8}$ per square centimeter, depending on the location, i.e., high flow through narrow pipes to stagnant or slow flow areas $15,27 \%$. Further generalizations concerning temporal and spatial differences, or differences between crops, will not be attempted here due to the limited data. 


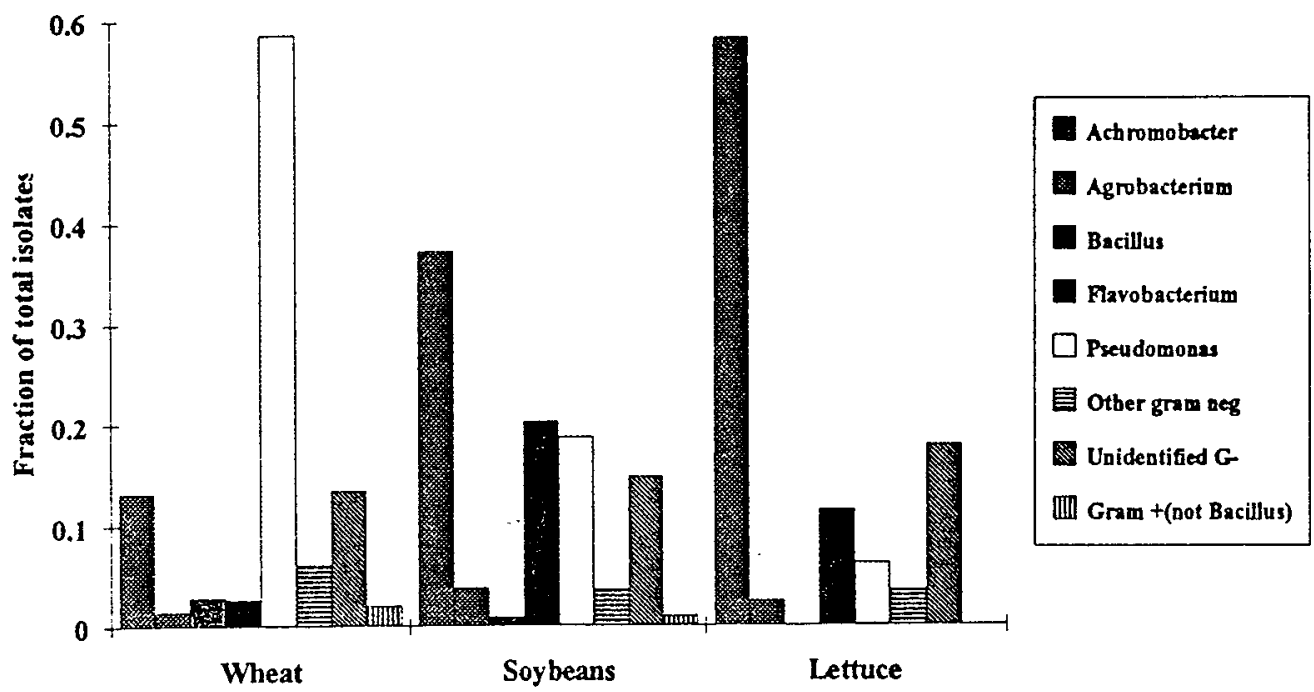

Fig. 3. Taxonomic distribution of the bacterial community associated with root surfaces of three crops grown in recirculating nutrient delivery systems at the KSC CELSS Biomass Production System. Bars represent the fraction of the total number of isolates that were identified. Isolates were obtained throughout the crop cycle for two wheat (ca. 540 isolates), three soybean (ca. 1080 isolates), and three lettuce (ca. 360 isolates) crops.

Microbial community composition-(taxonomic). Even fewer studies on biofilm community composition in recirculating systems were found than on abundance and distribution. Future research funding should emphasize this area.

\section{MICROBIAL PHYSIOLOGICAL FUNCTIONS}

\section{Carbon Transformations}

Mineralization of organic compounds. As a group, microorganisms can degrade nearly all naturally occurring and many anthropogenic organic compounds $/ 1$. The major sources of organic compounds in recirculating solution systems are rool exudates along with sloughed root (cap) cells. In addition, exogenous sources (graywater, crop residue leachate, aquaculture water) have at times been added with the intention of utilizing the metabolic capabilities of the system microflora to degrade the organic compounds contained in these solutions $77-1 \%$. The complex microbial community that develops in the various habitats of this ecosystem acts in concert to decompose nearly all of these compounds, although some of the more refractory ones may take a while. If microbial decomposition were limited or even eliminated, as could happen under some plant pathogen control strategies, many of these naturally occurring and/or added organics would accumulate. As rates of root exudation are generally low, this accumulation may be slow for the naturally occurring compounds.

Microbial metabolites. Several recent reviews by Lłnch have covered metabolites produced by rhizosphere microorganisms /30-31/. Many of these compounds may also be produced in the root zone of plants grown in recirculating systems. Compounds produced by isolates of root-associated microorganisms include plant growth regulators (ethylene, auxins, gibberellins, cytokinins, and abscisic acid), phytotoxic compounds (aliphatic acids, phenolic acids), siderophores (iron chelators), antibiotics, and various enzymes. In situ production of many of these compounds has been difficult to demonstrate as they can be active at nearty undetectable concentrations.

\section{Nitrogen Cycle Transformations}

Nitrogen fixation. $\mathrm{N}$ mineralization (ammonification), and $\mathrm{N}$ immobilization. Microorganisms perform key nitrogen transformations in most plant ecosystems. However, the nitrogen cycle in a recirculating system is somewhat truncated, because the nutrient solution is optimized to supply the form of nitrogen needed by the crop, irrespective of the metabolism of the microflora. Because 
the solution contains combined nitrogen, symbiotic or non-symbiotic nitrogen fixation probably does not occur. Nitrogen containing organic compounds are probably only a small fraction of the total organic content in a recirculating system, thus nitrogen mineralization, or conversion of organic- $\mathrm{N}$ to inorganic forms, although present, is probably unimportant to the total nitrogen nutrition of the crop. Sitnilarly, because the total microbial biomass of recirculating systems is low compared to the plant biomass, immobilization of inorganic nitrogen forms into microbial tissue is also probably insignificant.

Two nitrogen transformations that may still be of importance in a recirculating system, depending on the major form of inorganic nitrogen supplied to the plants, are denitrification and nitrification. Mass balance estimates for wheat $/ 32 /$ and white potatos $/ 33 /$ grown in recirculating systems have indicated that between 20 and $30 \%$ of the nitrate-nitrogen added could not be accounted. Denitrification, or bacterial conversion of nitrate into dinitrogen gas, was the suspected cause, and studies have been initiated to determine if this is so. Similarly, ammonium added to recirculating solutions of crops preferring this nitrogen source could be oxidized by nitrifying bacteria to nitrate. Although these crops can still utilize nitrate, loss of the preferred ammonium may affect crop growth.

\section{SOME THOUGHTS ON MICROBIAL COMMUNITIES AND PHYTOPATHOGEN CONTROL}

\section{Community Stability, Natural Selection and Homeostasis.}

The stresses of the physical, chemical, and biological components of the environment of recirculating systems have selected a microbial community that is a best fit for this unique set of parameters. The metabolic diversity of the inocula have ensured that most, if not all, niches are filled. although some functions are more efficiently accomplished than others. The community is exposed to modest and usually gradual fluctuations in these stresses, but remains largely unchanged, adjusting to all but the most extreme conditions. This homeostasis, or maintenance of community stability and integrity in a variable environment, is probably a reflection of species diversity and complexity /1\%. More diverse communities are more stable than those with less biological complexity.

Most aliens (phytopathogen, biocontrol agent, and, even other saprobes) fail to survive after introduction into such an already established microbial community /1/. The indigenous microflora reflect the environment, selection tends to preserve the status quo, and the invader is generally less fit than the microbes that have survived the prior selective pressures. Survival of an alien occassionally occurs and is probably due to either an unfilled niche or one that has been inefficiently filled (and the alien fills it better).

\section{Community Stability and Phytopathogen Control.}

Non-specific strategies for controlling plant pathogens will also cause alterations to the overall stability of the microbial community. If the control method causes permanent modifications to the recirculating environment, then appreciable establishment of a foreign phytopathogenic species could result. Often the response of the native community is a loss in species diversity, unfilled niches, or an inefficient filling of niches because the indigenous inhabitants are now less fit. Aliens entering the system may be berter able to fill these niches. If the control method is temporary, then the microbial community, through homeostasis, should eventually return to pre-control levels. However, during and immediately following the treatment, the microbial community could be more susceptible to survival of aliens.

If the phytopathogen control strategy were to non-specifically treat the inoculum sources, effectively removing nearly all microbes, then the overall diversity of the native microbial community in recirculating systems could also be diminished. Once again, as the diversity is simplified niches become unfilled or inefficently filled, and the survival of aliens could be increased.

Nelson has suggested that a constructed microbial community might be an answer to pathogen control $34 /$. However, such a constructed community would probably be too simple, because far too few species would be used. Considerable research would be needed to find the right mixture of isolates that could control all of the possible root pathogens that might be encountered. Furthermore. the presence of this community throughtout the life cycle of the crop would have to be established. The likelihood, again, is that unfilled or inefficiently filled niches will provide saprophytic phytopathogens/aliens with a chance to survive.

So. what can be done to control plant pathogens without adversely affecting the indigenous microbial community of recirculating systems? One possibility is to use very diverse, complex inoculated microbial communities from crops grown successully in the presence of (various) phytopathogen(s). For example, roots and soil from disease suppressive soils could be used as inocula /35/. These native microflora have already adapted to the pathogen and belp to control it. The exact control mechanism(s) are not always known, but why not let nature select the biocontrol agents?

A second possibility would be to develop, from an indigenous community, one that would naturally control the pathogen. This could entail continuous exposure of the community to attenuated phytopathogens (preferred) or to pathogen levels below critical threshhold numbers needed to elicit a disease. This approach is analogous to inoculating bumans with attenuated pathogens to develop an immunity to the disease. Precautions would be needed to ensure that the indigenous community has adapted to this changed 
cnvironment and that disease prevention occurs over a variety of circumstances. Continual exposure of the community to the pathogen (hopefully attenuated) would be necessary to ensure that the community does not de-adapt.

\section{REFERENCES}

1. M. Alexander, Microbial Ecology, J. Wiley, New York, 1971.

2. R.M Wheeler, C.L. Mackowiak T.W. Dreschel, J.C. Sager, R.P. Prince, W.M. Knoth C.R. Hinkle, and RF. Strayer, System development and early biiological tests in NASA's Biomass Production Chamber, NASA Technical Memorandum NASA-TM103494, Kennedy Space Center, FL, 1990.

3. M.E. Stanghellini and S.L. Rasmussen, this issue.

4. R. Evans and B. Vestergard, this issue.

5. RF. Strayer, Microbiological characterization of the Biomass Production Chamber during hydroponic growth of crops at the Controlled Ecological Life Support System (CELSS) breadboard facility, in: Regenerative Life Support Systems and Processes (SP873), ed. R.D. MacElroy, SAE Intemational, Warrendale, PA, 1991, p 36.

6. R.F. Strayer, unpublished results.

7. K. Wignarajah. D. Bubenheim. T. Wydeven, Jr., W. Berry, and G. Schlick, Growth of lettuce in anionic surfactants (Abstract), HortScience, 27, 655. 1992.

8. J.L. Garland and C.L. Mackowiak, Utilization of the water soluble fraction of wheat straw as a plant nutrient source, NASA Technical Memorandum. NASA-TM-103497, Kennedy Space Center, FL, 1990.

9. J.L. Garland, Coupling plant growth and waste recycling systems in a Controlled Life Support System (CELSS), NASA Technical Memorandum, NASA-TM-107544, Kennedy Space Center, FL, 1992.

10. L.P. Owens and C.R. Hall, Developing an aquaculture/agriculture system for manned space stations, Today's Aquaculiurist, 1, I.

11. M.V. Wiese. Compendium of wheat diseases, Amer.Phytopath.Soc., St. Paul MN, 1977.

12. J.O. Mundt and N.F. Hinkle, Bacteria within ovules and seeds. Appl.Environ.Microbiol. 32, 694. (1976)

13. C.L. Mackowiak, L.P. Owens, C.R. Hinkle, R.O. Prince, Continuous hydroponic wheal production using a recirculating system, NASA Technical Memorandum TM 102784, Kennedy Space Center, 1989.

14. B.G. Bugbee and F.B. Salisbury, Controlled environment crop production: Hydroponic vs. lunar regolith, in: Lunar base agriculture: soils for plant growth, ed. D.W. Ming and D.L. Henninger, American Society of Agronomy, Madison WI, 1989, p. 107.

15. S.H. Schwarzkopf. The effects of nutrient solution sterilization on the growth and yield of bydroponically grown lettuce, HoriScience, 22, 873. 1987.

16. N.A. Drugova, and L.S. Yunsova. Formation of microbe complex of wheat in closed systems, in: Role of lower organisms in recycling of substances in closed ecological systems, ed. V.A. Kordyum, Translation in NASA Technical Memorandum NASA-TM76484,1981 , p. 310

17. L.S. Tirranen, Microflora of chufa plants, a component of the closed ecosystem, in: Role of lower organisms in recycling of substances in closed ecological systems, ed. V.A. Kordyum, Translation in NASA Technical Memorandum NASA-TM-76484, 1981, p. 331.

18. R.M. Allas, Enumeration and estimation of microbial biomass, in Experimental microbial ecology, ed. R.G. Burns and J.H. Slater, Blackwell, Oxford, 1982, p. 84.

19. J.L. Garland, this issue.

20. G.D. Bowen and A.D. Rovira, Microbial colonization of plant roots, Ann.Rev.Phytopath. 14:121, 1976. 
21. G.D. Bowen, Misconceptions, concepts, and approaches in rhizosphere biology, in: Contemporary microbial ecologv, ed. D.C. Ellwood. J.M. Hedger, M.J. Latham, J.M. Lynch, and J.H. Slater, Academic Press, New York, 1980, p. 283.

22. J.M. Lynch, ed., The rhizosphere, J. Wiley, New York, 1990.

23. E.A. Curl and B. Truelove, The rhizosphere, Springer-Verlag. Berlin, 1986.

24. Y.R. Dommergues and S.V. Krupa, Interaction between non-pathogenic soil microorganisms and plants, Elsevier, Amsterdam, 1978.

25. J.M. Whipps, Carbon economy, in: The rhizosphere, ed. J.M. Lynch, J. Wiley, New York, 1990, p. 59.

26. A.D. Rovira and C.B. Davey, Biology of the rhizosphere, in: The plant root and its environment, ed. E.W. Carson, Univ. Press of Virginia, Charlottesville, VA, 1976, p. 153.

27. J.L. Garland. Carbon flux within hydroponically-based plant growth systems: analysis of microbial community structure and function. Ph.D. dissertation, Dept.Environ.Sci, U.Virginia, Charlottesville, VA, 1991.

28. W.G. Characklis and K.C. Marshall, ed., Biofilms, J. Wiley, New York, 1990.

29. W.G. Characklis, Biofilm processes, in: Biofilms, ed. W.G. Characklis and K.C. Marshall, J. Wiley, New York, 1990, p. 195.

30. J.M. Lynch. Microbial metabolites, in: The Rhizosphere, ed. J.M. Lynch, J. Wiley, New York 1990 p. 177.

31. J.M. Lynch, Products of soil microorganisms in relation to their plant growth. CRC Crit. Revs. Microbiol., 5, 67 (1976).

32. B.G. Bugbee, personal communication.

33. C.L. Mackoriak, personal commumication.

34. B. Nelson, The role of plant pathology in development of Controlled Ecological Life Support Systems, Plant Disease, 71, 580.

35. M.N. Schroth and J.G. Hancock, Disease suppressive soil and root-colonizing bacteria, Science, 216, 1376, (1982). 